\title{
Macrophage distribution in decidual tissue from early implantation to the periparturient period in mice as defined by the macrophage differentiation antigens $\mathrm{F} 4 / 80$, macrosialin and the type 3 complement receptor
}

\author{
J. M. Brandon \\ Department of Human Anatomy, University of Oxford, South Parks Road, Oxford OX13QX, UK
}

\begin{abstract}
Antibodies to differentiation markers have made it possible to identify macrophages in murine tissues. Macrophages are potent mediators of immunological reactions and it has been proposed that they are pivotal cells at the maternal-fetal interface. Studies of macrophage distribution in murine decidual tissue have provided conflicting evidence for and against the presence of significant numbers of macrophages at the maternal-fetal interface. The study described here used three independent macrophage differentiation antigens to examine the macrophage distribution in decidual tissue from day 6 to day 19 of pregnancy. Macrophage distribution was defined initially using a polyclonal antiserum to the plasma membrane differentiation antigen F4/80. Macrophages were virtually absent from antimesometrial decidual tissue until degenerating tissue was invaded by macrophages from about day 15 . The resident population of macrophages in the mesometrial stroma was retained when this area decidualized but these cells did not survive beyond day 13 . Mesometrial decidual tissue was virtually devoid of macrophages after this time. The metrial gland contained many macrophages until degeneration set in, but few were seen by day 15 of pregnancy. These distributions were confirmed using monoclonal antibodies $(\mathrm{mAb})$ to F4/80, macrosialin, a monocyte- and macrophage-specific membrane sialoprotein (mAb $\mathrm{FA} / 11$ ), and the leucocyte $\beta_{2}$-integrin CR3 (CDIIb/CD18; Mac-1), which is expressed on neutrophils as well as monocytes and some tissue macrophages. CR3 ${ }^{+}, \mathrm{F} 4 / 80^{-}$and $\mathrm{FA} / 11^{-}$neutrophils were found to be more widely distributed in decidual tissue than were $\mathrm{F} 4 / 80^{+}$or $\mathrm{FA} / 11^{+}$macrophages. Consideration of these observations led to the conclusion that decidual tissue does not support a resident or elicited population of macrophages and that macrophages are not normally found at the maternal-fetal interface in mice.
\end{abstract}

\section{Introduction}

The development of monoclonal antibodies to maturation markers on monocyte-derived cells has allowed recruited monocytes and macrophages to be identified in murine tissues (Gordon et al., 1992). The use of mono- and polyclonal antibodies to antigen F4/80 (Austyn and Gordon, 1981) has allowed mature macrophages to be identified as resident cells in many tissues (Hume and Gordon, 1985) including mesenchymal tissues of the reproductive tract (Hume et al., 1984; Redline and Lu, 1989; De and Wood, 1990; Brandon, 1993). The role of such resident cells is unclear but Hunt (1990) proposed that macrophages are pivotal cells in maternal-fetal immune interactions. Studies with $\mathrm{F} 4 / 80$ have found that mature macrophages are scarce in murine antimesometrial decidual tissue (De et al., 1991; Pollard et al., 1991; Brandon, 1993), an observation which has also been made in rats (Tachi and Tachi,

Received 19 April 1994
1986; Yelavarthi et al., 1991). However, the question of the presence or absence of macrophages in mesometrial decidual tissue, which forms the placental bed, remains unresolved, at least in part because of differing results between studies using F4/80 as the macrophage marker (Redline and Lu, 1989; Parr et al., 1990; versus Matthews et al., 1985; De and Wood, 1991).

The present study was undertaken to resolve this question. The distribution of $\mathrm{F} 4 / 80^{+}$macrophages was studied using wax-embedded tissues in which the location of positive cells could be clearly defined. The distribution of $\mathrm{F} 4 / 80^{+}$cells was confirmed using monoclonal antibody (mAb) F4/80 in cryosections and the study extended using monoclonal antibody FA/11, which identifies macrosialin, a membrane sialoprotein confined to murine mononuclear phagocytes and related cells (Rabinowitz and Gordon, 1991), and two mAbs against separate epitopes of the $\beta_{2}$-integrin CR3 (type- 3 complement receptor, CD11b/CD18, also known as Mac-1) (Springer, 1990) which identifies monocytes, some tissue macrophages, 


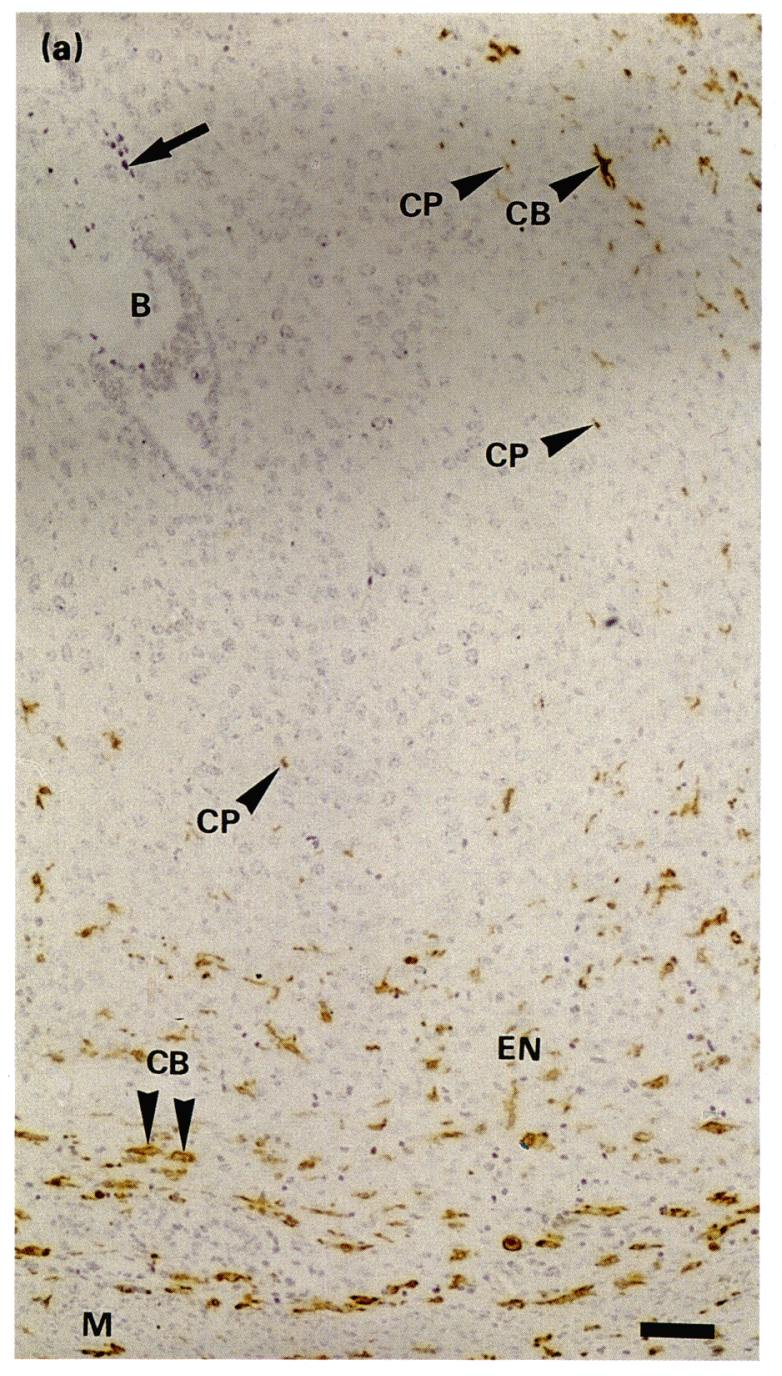

(b)

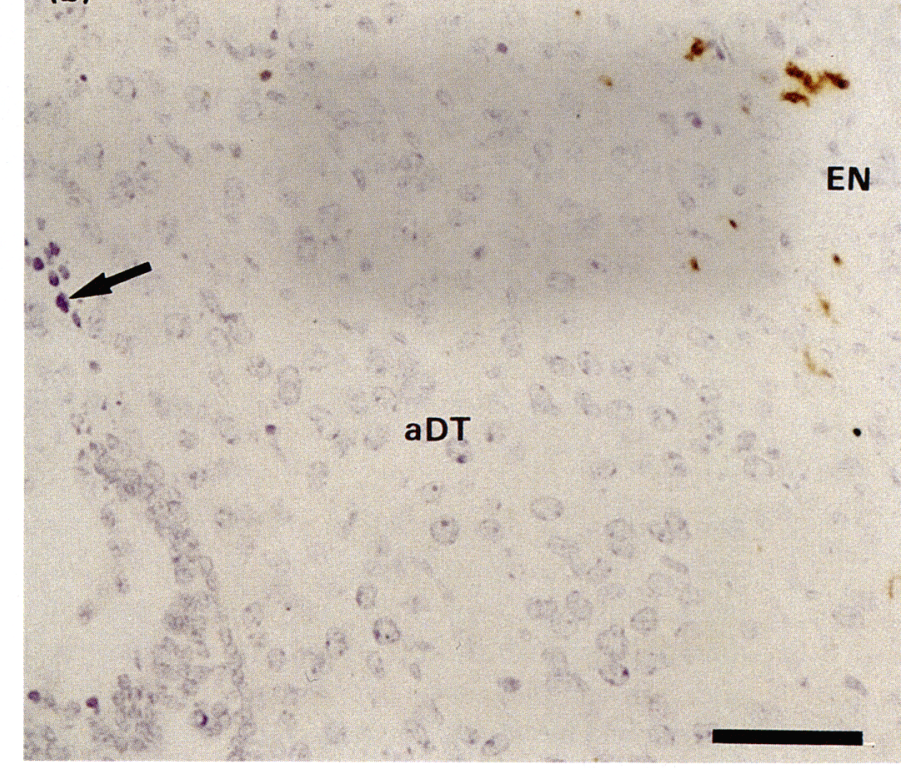

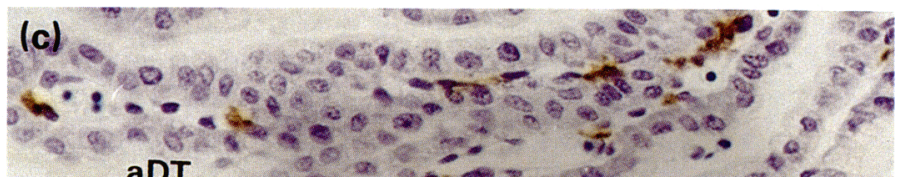

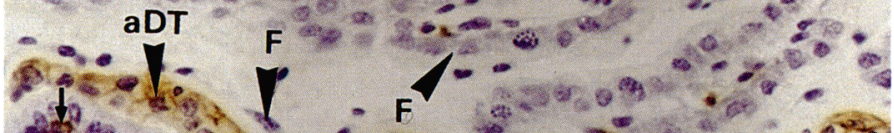

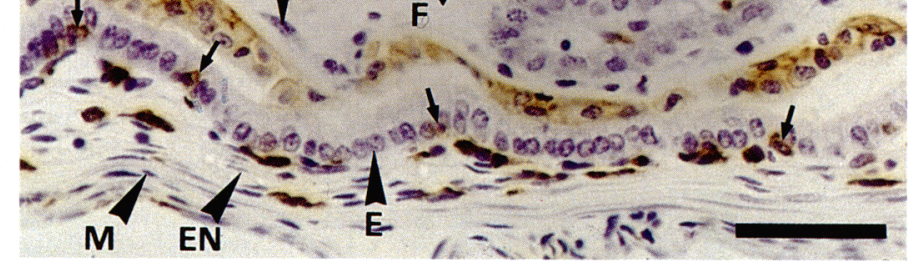
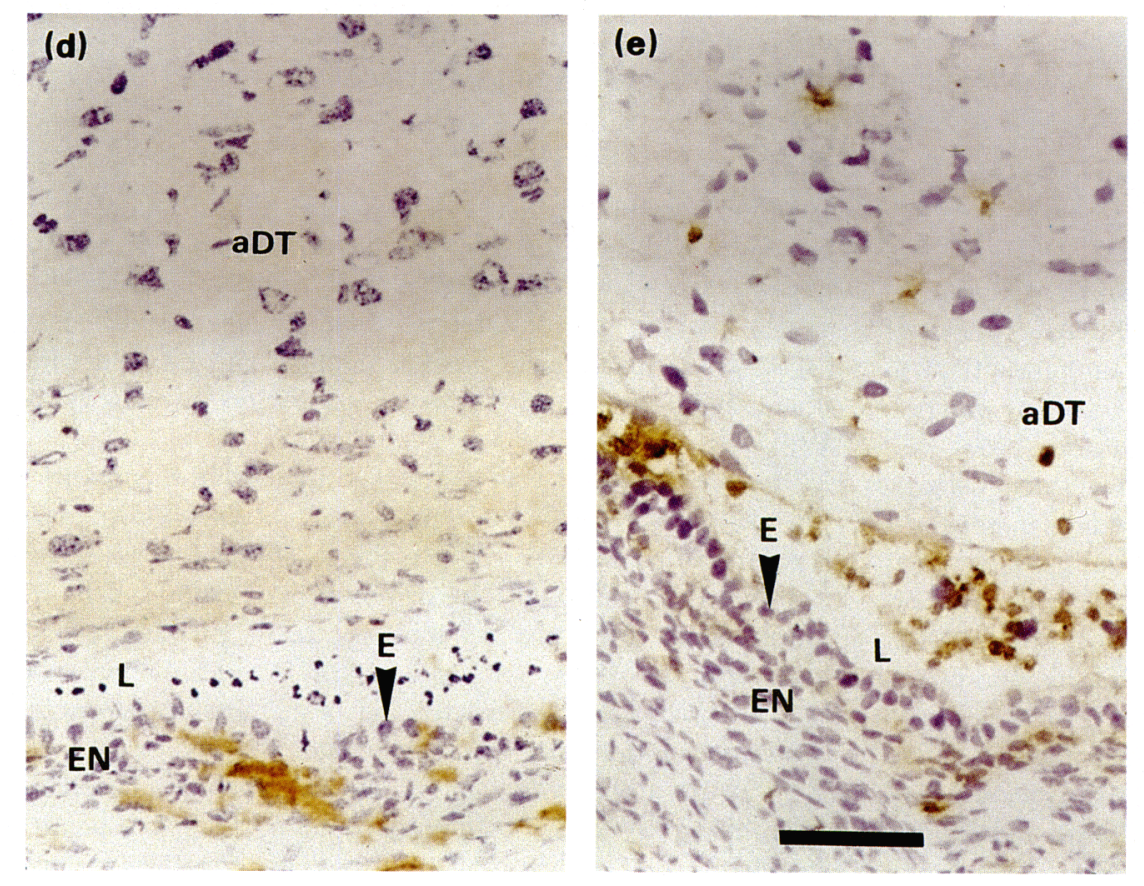

(f)

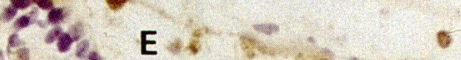

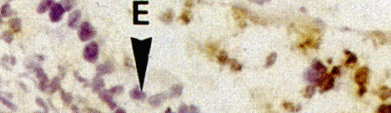

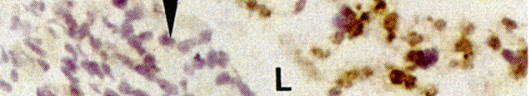

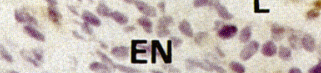
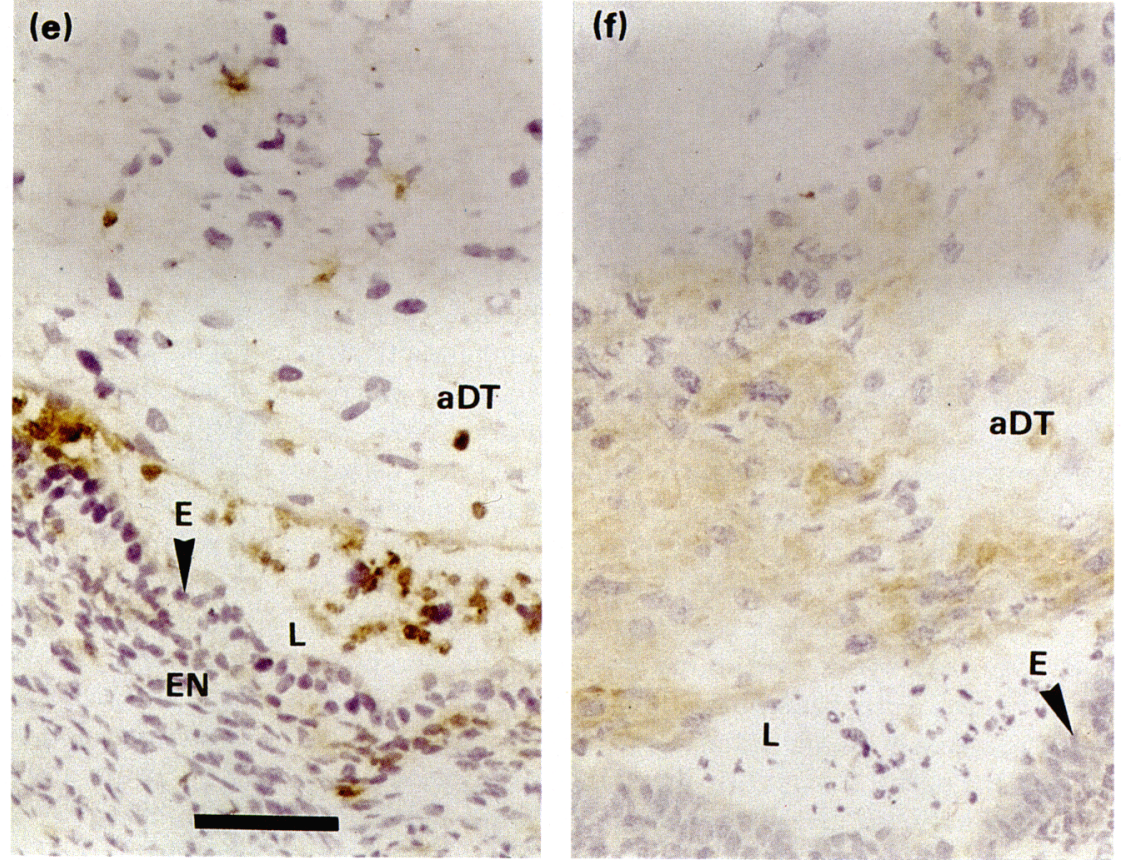
neutrophils and some natural killer cells (Crocker and Gordon, 1985; Lee et al., 1986).

\section{Materials and Methods}

\section{Animals}

Virgin female CD-I mice (Charles River UK, Margate) and phenotypically normal virgin females from the C3HE/101 FI hybrid colony (source of the hypogonadal mouse) maintained at this department were housed two to four to a cage with free access to laboratory food and water in a lighting cycle of $14 \mathrm{~h}$ light: $10 \mathrm{~h}$ dark. Females were placed with males and the morning on which a vaginal plug was found was designated day 1 of pregnancy. Females were killed by cervical dislocation or by asphyxiation using $\mathrm{CO}_{2}$, except on days 18 and 19 of pregnancy when animals were anaesthetized using tribromoethanol and perfused with periodate-lysine-paraformaldehyde (PLP) fixative (McClean and Nakane, 1974). Uteri were fixed and processed as described by Brandon (1993) except for uteri from days 18 and 19 which were immersed in PLP at $4^{\circ} \mathrm{C}$ for $24 \mathrm{~h}$ before being processed for wax embedding. Serial $7 \mu \mathrm{m}$ frozen or wax sections were cut and mounted. Frozen sections were stored at $-20^{\circ} \mathrm{C}$.

\section{Antibodies}

Polyclonal F4/80. The polyclonal rabbit antiserum to murine antigen F4/80 was obtained from S. Gordon (Sir William Dunn School of Pathology, Oxford). The F4/80 antigen is a membrane glycoprotein of unknown function. Affinity-purified antigen $\mathrm{F} 4 / 80$ was used to raise the monospecific polyclonal antiserum used in this study (Gordon ef al., 1992) and this was diluted 1:1000 or 1:2500 for staining. Nonimmune rabbit serum at the same dilution as the $\mathrm{F} 4 / 80$ was used as a control but nonspecific staining with rabbit serum was not seen.

Monocional antibodies. Monoclonal rat anti-mouse antibodies were obtained as tissue culture supernatants $(\mathrm{F} 4 / 80,5 \mathrm{C} 6$, M1/70) or ascites fluid (FA/11) from S. Gordon and, similarly, as supernatants (KT3) or ascites fluid (YTA 3.1) from M. Wood
(Department of Human Anatomy, Oxford). The antibodies were used as detailed below: $F 4 / 80$ ( $\operatorname{lgG} 2 \mathrm{~b}$, Austyn and Gordon, 1981) at 1:10; 5C6 (IgG2b, anti-CR3, Rosen and Gordon, 1987) in combination with $\mathrm{M} 1 / 70$ (IgG2b, anti-CR3, Beller et al., 1982), each at 1:10 to give a final antibody concentration of 1:5, FA/11 (IgG2a, anti-macrosialin, Rabinowitz and Gordon, 1991) at 1:20; KT3 (IgG2a, anti-CD3, pan T-cell marker, Tonomari, 1988) at 1:3; and YTA 3.1 (IgG2b, anti-CD4 antibody, Benjamin et al., 1988) at $1: 20$.

\section{Staining procedures}

The fixatives used with cryosections $\left(10-15 \mathrm{~min}\right.$ at $\left.4^{\circ} \mathrm{C}\right)$ were PLP (F4/80), buffered $1.5 \%$ paraformaldehyde ( $\mathrm{w} / \mathrm{v})$ (5C6 plus $\mathrm{M} 1 / 70, \mathrm{FA} / 11, \mathrm{YTA})$ and acetone $(\mathrm{KT} 3)$. The staining procedures for polyclonal $\mathrm{F} 4 / 80$ and monoclonal antibodies, based on Vectastain Elite ABC kits (Vector Labs, Peterborough), have been described by Brandon (1993).

Controls. Controls without exposure to primary antibody were used in all stains, and controls without primary and secondary antibodies were used for each fixative. Cells with peroxidase-positive granules, assumed to be eosinophils, were seen in some uteri.

\section{Results}

Representative views of antimesometrial and mesometrial decidual tissue from the post-attachment phase to late pregnancy are shown (Figs 1 and 2, respectively).

\section{The distribution of antigen $F 4 / 80$ using polyclonal antibody}

Antigen $\mathrm{F} 4 / 80$ was well preserved in wax-embedded tissues with clear staining of macrophages, most of which showed stellate morphology (Figs $1 \mathrm{a}, \mathrm{b}$ and $2 \mathrm{a}$ ). The cell processes of stellate macrophages were clearly defined with wax-embedded, $\mathrm{pF} 4 / 80$-stained material. Carnoy's is a dehydrating fixative and will cause significant shrinkage of tissues but is recommended for good cytological and nuclear preservation. The histology of

Fig. 1. Aspects of antimesometrial decidual tissue from the post-attachment phase to late pregnancy. (a-c) Wax-embedded sections stained using polyclonal F4/80 and counterstained with cresyl violet: (d-f) Cryosections stained using monoclonal antibodies. (d) F4/80; (e) M1/70 plus 5C6; (f) KT3, and counterstained with cresyl violet. (a) Sagittal section through an implantation site at day 6 of pregnancy and (b) higher power view of one area of the same section, showing antimesometrial decidual tissue $(\mathrm{aDT})$ and untransformed endometrium (EN) and myometrium (M). The arrows indicate the same point in both sections. $\mathrm{F} 4 / 80^{+}$macrophages can be seen to be excluded from the area of cells that show the enlarged nuclei of typical decidual cells. The undecidualized endometrium contains many sections through the cell bodies (CB) of F4/80 ${ }^{+}$irregularly shaped macrophages and sections through $\mathrm{F} 4 / 80^{+}$cell processes (CP). B: blastocyst. (c) Transverse section through an implant at day 15 of pregnancy showing the remains of the aDT infiltrated with $\mathrm{F} 4 / 80^{+}$macrophages which can also be seen in the endometrium (EN) and myometrium (M) underlying the re-established luminal epithelium (E), and within the luminal epithelium (arrows). F: fetal membranes. (d) Sagittal section through the aDT of an implant at day 10 of pregnancy stained using monoclonal F4/80 to show tissue macrophages. No F4/80 ${ }^{+}$cells are seen in the decidual tissue or the uterine lumen (L), although many $\mathrm{F} 4 / 80^{-}$cells are seen in the lumen. $\mathrm{F} 4 / 80^{+}$macrophages are seen in the untransformed endometrium (EN) underlying the luminal epithelium (E). (e) A section from the same area as that shown in (d) stained using the anti-CR3 antibodies, M1/70 and 5C6, to demonstrate neutrophils, monocytes and some macrophages. CR ${ }^{+}$cells are seen within the aDT and the lumen (L) as well as the untransformed endometrium (EN) underlying the luminal epithelium (E). ( $\mathrm{f}$ ) A section through the same area as that shown in (d) and (e) stained using the anti-lymphocyte antibody KT3, illustrating the nonspecific coloration of decidual tissue which was sometimes seen with monoclonal antibodies. Scale bars represent $50 \mu \mathrm{m}$. 


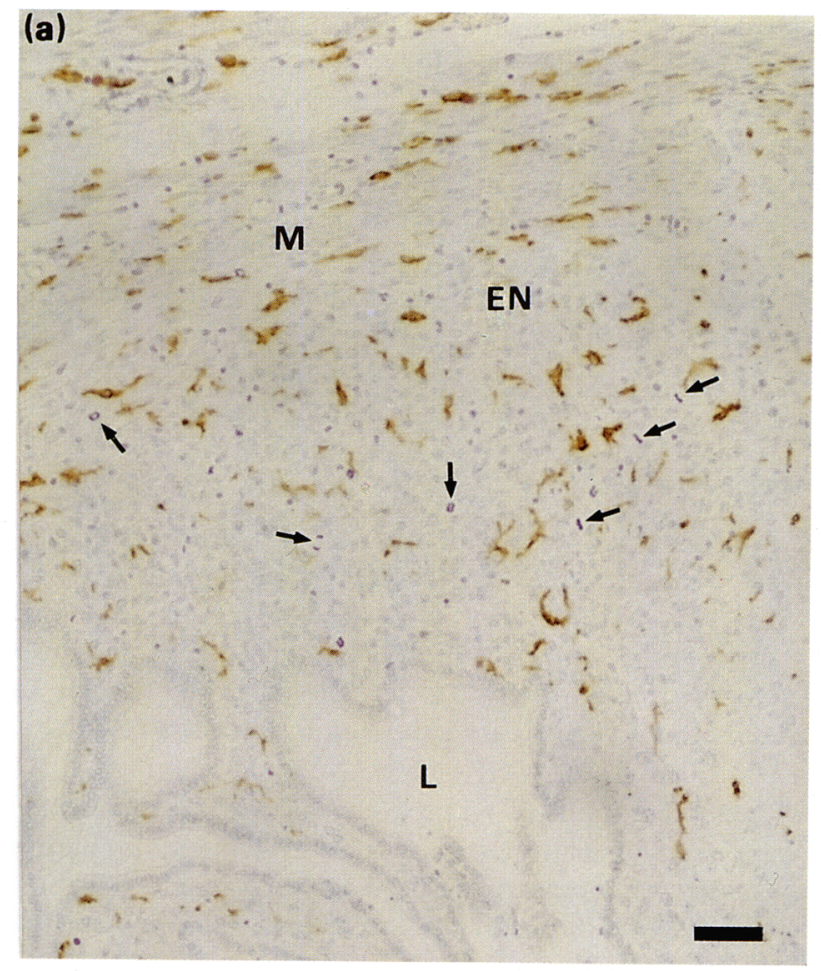

(b)

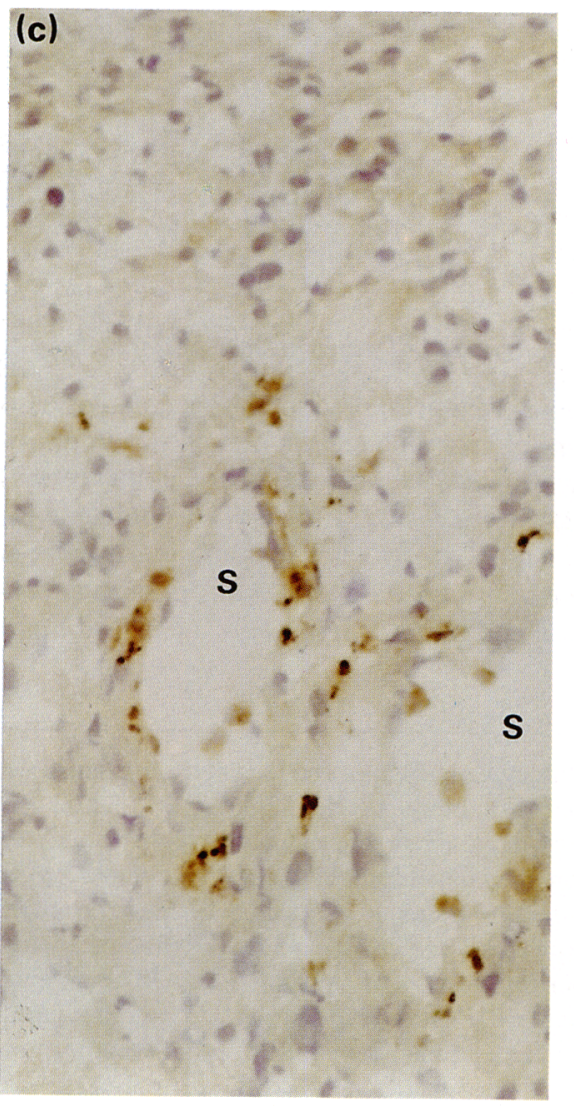

(d)

S

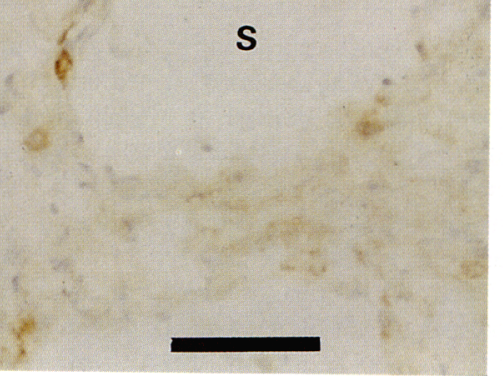

(e)

S

s

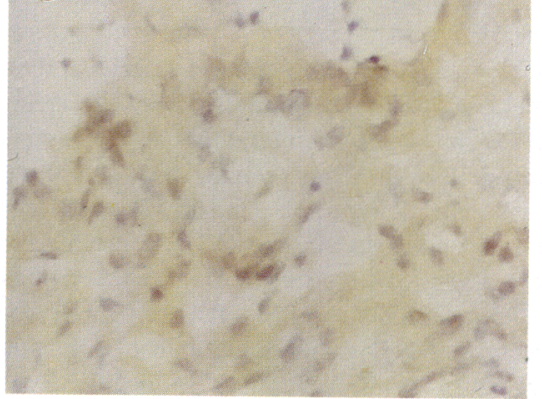


Table 1. Analysis of the occurrence of $\mathrm{F} 4 / 80^{+}$cells, as revealed by the use of a polyclonal antibody to antigen $\mathrm{F} 4 / 80$, in antimesometrial decidual tissue, mesometrial decidual tissue and the metrial gland from day 6 to day 19 of pregnancy

\begin{tabular}{lccccc}
\hline & Days 6-7 & Days 8-9 & Days 10-12 & Days 13-15 & Days 16-19 \\
\hline Number of animals & 18 & 4 & 6 & 4 & 8 \\
Number of sites & 63 & 8 & 17 & 7 & 9 \\
Antimesometrial decidual tissue & $\pm^{\mathrm{a}}$ & $\pm{ }^{\mathrm{ab}}$ & - & + & $+{ }^{c}$ \\
Mesometrial decidual tissue & $+{ }^{+}$ & ++ & + & + & + \\
Metrial gland & $+{ }^{\mathrm{d}}$ & + & ++ & + & \pm
\end{tabular}

\footnotetext{
- : few $\mathrm{F} 4 / 80^{+}$cells seen in any section; \pm : a few $\mathrm{F} 4 / 80^{+}$cells seen in most sections; + : numbers of $\mathrm{F} 4 / 80^{+}$cells lower than in endometrium between sites; ++ : numbers of $\mathrm{F}_{4} / 80^{+}$cells within the normal range for undecidualized endometrium.

"Many $\mathrm{F}_{4} / 8 \mathrm{O}^{+}$cells were found in the periphery of antimesometrial decidual tissue. The boundary between decidualized and undecidualized cells could not be accurately defined.

"Some $\mathrm{F} 4 / 80^{+}$cells found in maternal blood in the lumen around the embryo.

"Antimesometrial tissue was not discernible in day $18-19$ uteri except at the junction with mesometrial decidual tissue

${ }^{\mathrm{A}}$ Area where the metrial gland will develop.
}

the uterus was excellent in Carnoy-fixed sections, although cytoplasmic granules, such as those of mast cells and eosinophils, were not well preserved. The different zones of decidual tissue and regions of the trophoblast and placenta could be seen clearly.

Implantation sites from 40 animals were stained with $\mathrm{pF} 4 / 80$ and the results are summarized in Table $1 . \mathrm{F} 4 / 80^{+}$cells were very rarely seen within the antimesometrial decidual tissue from day 6 (Fig. Ia, b) until this area was reduced to a thin layer at about day 15 , when it was infiltrated with $\mathrm{F} 4 / 80^{+}$ macrophages (Fig. Ic). The myometrium and undecidualized areas of the endometrium between implants contained many $\mathrm{F} 4 / 80^{+}$cells on day 6 (Figs 1a and 2a) and this distribution continued throughout pregnancy. Many macrophages remained in the untransformed endometrium peripheral to the antimesometrial decidual tissue. This untransformed layer became increasingly compressed as the antimesometrial decidual tissue expanded and was no longer seen in areas of decidual tissue where the luminal epithelium had been re-established. The uterine lumen is discontinuous after decidualization has occurred and is re-established around the outside of the antimesometrial and lateral decidual tissue by outgrowth from areas of epithelium between implants (Welsh and Enders,
1983). Figure 1c is taken from the central region of a day 15 site and shows the remains of antimesometrial decidual tissue between the parietal wall of the yolk sac and the re-established epithelium. This period of association between degenerating antimesometrial decidual tissue and macrophages was the only time when $\mathrm{F} 4 / 80^{+}$cells were found in the uterine lumen except for a brief period around days $8-9$ when a few F $4 / 80^{+}$ cells were seen in the maternal blood in the lumen around the embryo.

The mesometrial stroma was compressed by the enlarged antimesometrial stroma on day 6 (Fig. 2a). Enlargement and decidual transformation of the mesometrial stroma was evident from day $8 . \mathrm{F} 4 / 80^{+}$cells found in the untransformed mesometrial stroma were retained $i n$ situ when this area decidualized but did not increase in number, although the mesometrial decidual tissue increased in size. This meant that $\mathrm{F} 4 / 80^{+}$cells were much more widely spaced in the decidualized mesometrial area than they were before decidual transformation. Almost all of these mesometrial $\mathrm{F} 4 / 80^{+}$cells were found within the decidual tissue rather than in blood sinusoids (Fig. 2b). Conspicuously fewer $\mathrm{F} 4 / 80^{+}$cells were found in mesometrial decidual tissue by day 13 and this area was virtually devoid of $\mathrm{F} 4 / 80^{+}$cells from day 15 .

\footnotetext{
Fig. 2. Aspects of mesometrial decidual tissue from the post-attachment phase to late pregnancy. (a) and (b) Wax-embedded sections stained using polyclonal F4/80 and counterstained with cresyl violet. (c-e) Cryosections stained using monoclonal antibodies (c) M1/70 plus 5C6; (d) F4/80; (e) YTA 3.1, and counterstained with cresyl violet. (a) Sagittal section through an implantation site at day 6 of pregnancy showing the undecidualized mesometrial endometrium (EN) and myometrium (M). This view is taken from the same section as that shown in Fig. 1a. F4/80 ${ }^{+}$macrophages are found throughout the undecidualized endometrium. Many mitoses can be seen in the mesometrial stroma (arrows). L: lumen. (b) Sagittal section through the sinusoidal zone of the mesometrial decidual tissue (mDT) from an implant at day 10 of pregnancy showing $\mathrm{F}_{4} / 80^{+}$ macrophages quite widely spaced within the decidual tissue but not in the sinusoids $\left(\mathrm{S}\right.$ ). The rounded shape of the F4/80 ${ }^{+}$cells seen here is typical of macrophages found within mesometrial decidual tissue and contrasts with the more irregularly shaped macrophages found in the undecidualized endometrium. The functional significance of the change in shape is not known. (c) Sagittal section through the mDT of an implant at day 16 of pregnancy stained with the anti-CR3 antibodies, M1/70 and $5 \mathrm{C} 6$, to demonstrate neutrophils, monocytes and some tissue macrophages. CR $3{ }^{+}$ cells are seen within the mDT and within blood sinusoids (S). Many of the CR3 ${ }^{+}$cells found within the mDT in sites examined after day 13 of pregnancy were close to blood vessels. (d) Section from the same area as that shown in (c) stained using monoclonal F4/80 to show tissue macrophages. Very few F4/80 ${ }^{+}$cells were found in $\mathrm{mDT}$ at day 16 of pregnancy and those few were always close to blood vessels. The area illustrated here contained more $\mathrm{F} 4 / 80^{+}$cells than did most other areas of $\mathrm{mDT}$ examined after day 13 of pregnancy. (e) Section through the same area as that shown in (c) and (d) stained using the anti-CD4 lymphocyte antibody YTA 3.1. No lymphocytes were seen in the mDT at any time. Scale bars represent $50 \mu \mathrm{m}$.
} 
The metrial gland contained many $\mathrm{F} 4 / 80^{+}$cells and their number increased until degeneration was evident from day 13 (Stewart and Peel, 1978). Numbers of metrial gland $\mathrm{F} 4 / 80^{+}$ cells were reduced by day 15 and few were seen later in pregnancy.

The placenta contained $\mathrm{F} 4 / 80^{+}$cells from days $12-13$. The distribution of $\mathrm{F} / 80^{+}$cells within the placenta and fetal membranes was similar to that reported by Redline and Lu (1989) and Morris et al. (1991). F4/80 ${ }^{+}$cells were not found in the giant cell layer or the spongiotrophoblast, but were plentiful in the placental labyrinth.

\section{The distribution of $\mathrm{F} 4 / 80^{+}, \mathrm{FA} / 11^{+}$and $\mathrm{CR} 3^{+}$cells using monoclonal antibodies}

Studies with other macrophage-related antibodies were undertaken to confirm and further investigate the distributions seen using $\mathrm{pF} 4 / 80$. Monoclonal $\mathrm{F} 4 / 80$ was used in $1-4$ sites from 17 mice killed on days $8-16 ; 5 \mathrm{C} 6$ plus $\mathrm{M} 1 / 70$ in $1-4$ sites from 12 mice killed on days $8-16$; and FA/ 11 in $1-2$ sites from three mice killed on days $8-9$ and three mice killed on days 13-16. The distribution of $\mathrm{FA} / 11^{+}$and $\mathrm{mF} 4 / 80^{+}$cells in antimesometrial decidual tissue was similar to that described for $\mathrm{pF} 4 / 80^{+}$cells. $\mathrm{FA} / 11^{+}$cells were more numerous than $\mathrm{F} 4 / 80^{+}$cells in the mesometrial decidual tissue and some of the $\mathrm{FA} / 11^{+}$cells were found within blood vessels, reflecting the presence of monocytes which are known to be FA/1I ${ }^{+}$and F4/80- (Gordon et al., 1992). Few $\mathrm{FA}_{111}{ }^{+}$or $\mathrm{F} 4 / 80^{+}$cells were seen in mesometrial decidual tissue or within the blood sinusoids on days 13-16 (Fig. 2d), aithough many were found in the antimesometrial endometrium associated with the re-established luminal epithelium and some were seen in the new lumen. Like $\mathrm{pF} 4 / 80^{+}$cells, $\mathrm{FA} / 11^{+}$and $\mathrm{mF} 4 / 80^{+}$cells were closely associated with the degenerating antimesometrial decidual tissue on days 15-16.

Conspicuously more $\mathrm{CR} 3^{+}$than $\mathrm{F}_{4} / 80^{+}$or $\mathrm{FA} / 11^{+}$cells were seen in mesometrial decidual tissue (Fig. 2c, d) and, in contrast to $\mathrm{F} 4 / 80$ and $F A / 11$, antimesometrial decidual tissue contained some CR $3^{+}$cells (Fig. Id, e). Many of the decidual $\mathrm{CR}^{+}$cells were found within blood vessels, but some were seen within the decidual tissue (Fig. $2 \mathrm{c}$ ). $\mathrm{CR}^{+}$cells were also found in the lumen at all times, both between implants and adjacent to the embryo. The presence of $\mathrm{CR} 3^{+} \mathrm{F} 4 / 80^{-}$cells in the lumen and antimesometrial decidual tissue on day 10 is shown in Fig. 1 (d, e). These luminal $\mathrm{CR} 3^{+}$cells were also $\mathrm{FA} / 11^{-}$, confirming their identification as neutrophils, not monocytes. Fewer $\mathrm{CR}^{+}$cells were seen on days 15-16 than on days $9-10$, but there were still more CR $3^{+}$cells than $\mathrm{FA} / 11^{+}$or $\mathrm{F} 4 / 80^{+}$cells (Fig. $2 \mathrm{c}$, d). It was notable that the anti-CR3 antibodies stained fewer cells in the untransformed endometrium and the myometrium than $\mathrm{F} 4 / 80$ in all sites studied, reflecting the lack of CR3 expression on some tissue macrophages (Crocker and Gordon, 1985; Gordon et al., 1992). $\mathrm{CR}^{+}{ }^{+}$endometrial macrophages were more common in the basal endometrium of untransformed areas than in the subepithelial region, in all sites. $\mathrm{F} 4 / 80^{+}$macrophages were evenly distributed within the untransformed endometrium. The monoclonal antibodies showed the same distribution within the metrial gland as found with polyclonal F4/80, with a decrease in the number of positive cells from days 8-10 to days 13-16.

\section{Controls}

The anti-lymphocyte antibodies, KT3 and YTA 3.1, stained few cells in any section (Figs if and 2e) and the cells stained were of a different distribution and morphology from those stained with the anti-macrophage antibodies. Degenerating antimesometrial and lateral areas of the decidual tissue and, on some occasions, mesometrial decidual tissue were discoloured after the use of chromogen in some cryosections not exposed to primary $\mathrm{mAb}$ and in some of those exposed to the various $m A b s$ (Fig. If). This nonspecific staining was easily differentiated from the more intense and localized membrane- or vesicle-bound antibody stains.

Several experiments were performed in an attempt to reproduce the results of De and Wood (1991), who found that nearly all mesometrial decidual cells were $\mathrm{F} 4 / 80^{+}$using staining procedures similar to those used here. Several fixatives were compared (acetone, buffered paraformaldehyde, PLP); the initial step using serum to block nonspecific reaction to the secondary antibody was omitted (De and Wood, 1991) and the $\mathrm{pH}$ of the PBS used for diluting agents and rinsing slides was varied ( $\mathrm{pH} \mathrm{5,6}$ and 7 ). None of these procedures resulted in $\mathrm{F} 4 / 80^{+}$staining of decidual cells.

\section{Discussion}

The study described here using three independent macrophage marker antigens has shown that, in contrast to untransformed endometrium, decidual tissue does not support a resident population of macrophages, in mice. The macrophage population of decidual tissue varied with location and time. This evidence supports the proposals that antimesometrial decidual tissue is virtually devoid of macrophages until it becomes degenerate, and that mesometrial decidual tissue is virtually devoid of macrophages after day 13 of pregnancy.

Macrophages were plentiful in untransformed endometrium and myometrium but were only found in the uterine lumen for a brief period around days 8-9 when blood accumulated around the embryo as invading trophoblast cells penetrated maternal vessels, and from about day 15 when the degenerate antimesometrial decidual tissue was being phagocytosed. Macrophages could have gained access to the degenerating antimesometrial decidual tissue by migrating into the new uterine lumen, which is established around the outside of the antimesometrial and lateral decidual tissue (Welsh and Enders, 1983). The endometrium associated with the new luminal epithelium contained many $\mathrm{F} 4 / 80^{+}$macrophages and, in contrast to areas between implants, some $\mathrm{F} 4 / 80^{+}$cells were seen within this epithelium. Neutrophils were found in all areas of the lumen at all times.

The population of macrophages found in the mesometrial endometrium before decidual transformation was retained after transformation, but there was no increase in the number of macrophages in line with the increase in numbers of decidual cells and the macrophages in mesometrial decidual tissue did not survive beyond day 13 of pregnancy. After this time 
mesometrial decidual tissue was virtually devoid of macrophages. The lack of $\mathrm{F} 4 / 80^{+}$macrophages in mesometrial decidual tissue in late pregnancy has been reported by Redline and Lu (1989) and Parr et al. (1990). Mesometrial decidual tissue was not infiltrated by macrophages even when it was seen to be degenerating on days 18-19 of pregnancy. This failure to infiltrate degenerating mesometrial decidual tissue may be associated with the ability of the decidual tissue substratum to inhibit macrophage motility and function (Redline et al., 1990; McKay et al., 1992).

The present study illustrates the drawbacks of using antiCR3 antibodies to demonstrate tissue macrophages. More macrophages were seen in undecidualized tissues using F4/80 or FAVII rather than the anti-CR3 antibodies, and the presence of $\mathrm{CR}^{+}$neutrophils within decidual tissue complicated the assessment of macrophage distribution. Although nuclear morphology can differentiate between $\mathrm{CR} 3{ }^{+}$cells, newly recruited murine monocytes-macrophages often have horseshoe-shaped nuclei that could be confused with polymorphic neutrophil nuclei, and antibody staining may obscure the nuclear morphology of some cells. Stewart and Mitchell (1991), using the Mac-1 (M1/70) antibody, reported that most uterine macrophages were located in the myometrium, mesometrium and basal endometrium, while this study, and others using F4/80 (De and Wood, 1991; De et al., 1991; Brandon, 1993, 1994), have shown that large numbers of macrophages can be found throughout the endometrium. Stewart and Mitchell (1991, 1992) demonstrated a qualitatively similar distribution of $\mathrm{CR}^{+}$cells in mid- to late pregnancy decidua to that reported here but detected fewer $\mathrm{CR} 3^{+}$cells. This may be attributable to the use of antibodies to two different epitopes of CR3 in the present study. The more specific antimacrophage antibodies, $\mathrm{F} 4 / 80$ and $F A / 11$, give a clear indication of changes in macrophage distribution without the complications introduced by $\mathrm{CR} 3{ }^{+}$neutrophils and CR $3{ }^{-}$macrophages.

The good histology of wax-embedded sections stained with polyclonal $\mathrm{F} 4 / 80$ showed that the resident macrophage population in the antimesometrial endometrium is displaced towards the myometrium as stromal cell division and decidual transformation progress outwards from the attachment site, giving rise to a band of macrophage-rich undecidualized tissue peripheral to the decidual tissue. In contrast, in the mesometrial endometrium of the attachment site, decidual transformation is initiated throughout the region rather than as an advancing front, and resident macrophages remain in place as the stromal cells around them divide and transform.

Macrophages have been found in short-term cultures of murine decidual tissue (e.g. Matthews et al., 1985). Recovery of macrophages from decidual tissue stripped from uteri may be due to contamination of the decidual tissue with the compressed basal layer of undecidualized endometrium, which contains many macrophages, or to the use of mesometrial decidual tissue before the loss of resident macrophages at about day 13 .

The present work corroborates other histological studies indicating a lack of macrophage-specific markers in decidual tissues of rats (Tachi and Tachi, 1986; Yelavarthi et al., 1991) and mice (Redline and Lu, 1989; Parr et al., 1990; Pollard et al., 1991), but contradicts the observations of De and Wood (1991) who found that virtually all murine decidual cells were $\mathrm{F} 4 / 80^{+}$.
Attempts were made to repeat the observations of $\mathrm{De}$ and Wood (1991), but were without success. The lack of macrophages in decidual tissue and the evidence that the substratum of decidual tissue inhibits macrophage functions suggest that mononuclear phagocytes are probably not involved in immune responses at the maternal-fetal interface in healthy pregnancies in mice.

The author thanks S. Gordon (Sir William Dunn School of Pathology, University of Oxford) and M. Wood (Department of Human Anatomy, University of Oxford) for the generous supply of antibodies, and C. Simpson and M. John for technical assistance. This investigation received financiai support from the Special Programme of Research, Development and Research Training in Human Reproduction, World Health Organization, the Medical Research Council and The Wellcome Trust.

\section{References}

Austyn JM and Gordon S (1981) F4/80; a monoclonal antibody directed specifically against the mouse macrophage European Journal of Immunology 11 805-811

Beller DI, Springer TA and Schreiber RD (1982) Anti Mac-1 selectively inhibits the human type 3 complement receptor journal of Experimental Medicine 156 1000-1009

Benjamin RJ, Shixin Q, Wise MP, Cobbold SP and Waldemann H (1988) Mechanisms of monoclonal antibody-facilitated tolerance induction: a possible role for the CD4 (L3T4) and CD11a (LFA-1) molecules in self-non-self discrimination European Journal of Immunology 18 1079-1088

Brandon JM (1993) Leucocyte distribution in the uterus during the preimplantation period of pregnancy and phagocyte recruitment to sites of blastocyst attachment in mice Journal of Reproduction and Fertility $98567-576$

Brandon JM (1994) Distribution of macrophages in the mouse uterus from one day to three months after parturition, as defined by the immunohistochemical localization of the macrophage-restricted antigens F4/80 and macrosialin. Anatomical Record 240 233-242

Crocker $\mathbf{P}$ and Gordon $\mathbf{S}$ (1985) Isolation and characterization of resident stromal macrophages and haematopoietic cell clusters from mouse bone marrow Journal of Experimental Medicine 162 993-1014

De $M$ and Wood GW (1990) Influence of oestrogen and progesterone on macrophage distribution in the mouse uterus Joumal of Endocrinology 216 417-424

De $M$ and Wood GW (1991) Analysis of the number and distribution of macrophages, lymphocytes, and granulocytes in the mouse uterus from implantation through parturition Journal of Leukocyte Biology $\mathbf{5 0}$ 361-392

De M, Choudhuri R and Wood GW (1991) Determination of the number and distribution of macrophages, lymphocytes, and granulocytes in the mouse uterus from mating through implantation Journal of Leukocyte Biology $\mathbf{5 0}$ $252-262$

Gordon S, Lawson L, Rabinowitz S, Crocker PR, Morris L and Perry VH (1992) Antigen markers of macrophage differentiation in murine tissues Current Topics in Microbiology and Immunology 181 I-37

Hume DA and Gordon S (1985) The mononuclear phagocyte system of the mouse defined by immunohistochemical localisation of antigen F4/80. In Mononuclear Phagocytes. Characteristics, Physiology and Function pp 9-17 Ed. R van Furth. Martinus Nijhoff, Dordrecht, Boston, Lancaster

Hume DA, Halpin D, Charlton H and Gordon S (1984) The mononuclear phagocyte system of the mouse defined by immunohistochemical localisation of antigen F4/80. Macrophages of endocrine organs Proceedings of the National Academy Sciences USA 81 4171-4177

Hunt JS (1990) The role of macrophages in the uterine response to pregnancy Placenta $11467-475$

Lee S-H, Crocker P and Gordon S (1986) Macrophage plasma membrane and secretory properties in murine malaria. Effects of Plasmodium yoelii infection on macrophages in the liver, spleen and blood journal of Experimental Medicine $16354-74$ 
McClean IW and Nakane PK (1974) Periodate-lysine-paraformaldehyde fixative. A new fixative for immuno-electron microscopy Journal of Histochemistry and Cytochemistry 22 1077-1083

McKay DB, Vazquez MA, Redline RW and Lu CY (1992) Macrophage functions are regulated by murine decidual and tumor extracellular matrices Journal of Clinical lnvestigation 89 134-142

Matthews CJ, Adams AM and Searle RF (1985) Detection of macrophages and the characterization of $F_{C}$ receptor bearing cells in the mouse decidua, placenta and yolk sac using the macrophage-specific monoclonal antibody F4/80 Journal of Reproductive Immunology 7 315-323

Morris L, Graham CF and Gordon S (1991) Macrophages in haemopoietic and other tissues of the developing mouse detected by monoclonal antibody F4/80 Development 112 517-526

Parr EL, Young LHY, Parr MB and Young JD-E (1990) Granulated metrial gland cells of pregnant mouse utenus are natural killer-like cells that contain perforin and serine esterases Journal of Immunology 145 2365-2372

Pollard GW, Hunt JS, Wiktor-Jedrzejczak W and Standley ER (1991) A pregnancy defect in the osteopetrotic (oplop) mouse demonstrates the requirement for CSF-1 in female fertility Developmental Biology 148 273-283

Rabinowitz SS and Gordon S (1991) Macrosialin a macrophage-restricted membrane sialoprotein differentially glycosylated in response to inflammatory stimuli Journal of Experimental Medicine 174 827-836

Redline RW and Lu CY (1989) Localization of fetal major histocompatibility antigens and maternal leukocytes in murine placenta Laboratory Investigation $6127-36$

Redline RW, McKay DB, Vazquez MA, Papaioannou VE and Lu CY (1990) Macrophage functions are regulated by the substratum of murine decidual stromal cells Journal of Clinical Investigation 85 1951-1958
Rosen H and Gordon S (1987) Monoclonal antibody to the murine type 3 complement receptor inhibits adhesion of myelomonocytic cells in vitro and inflammatory recruitment in vivo Journal of Experimental Medicine 166 1685-1701

Springer TA (1990) Adhesion receptors of the immune system Nature 346 425-434

Stewart IJ and Mitchell BS (1991) The distribution of uterine macrophages in virgin and early pregnant mice Journal of Anatomy 179 183-196

Stewart IJ and Mitchell BS (1992) Macrophages and other endocytotic cells in the mouse uterus during the second half of pregnancy and into the postpartum period Journal of Anatomy 181 119-126

Stewart 1 and Peel S (1978) The differentiation of the decidua and the distribution of metrial gland cells in the pregnant mouse uterus Cell and Tissue Research 187 167-179

Tachi C and Tachi S (1986) Macrophages and implantation Annals of the New York Academy of Sciences 476 I58-182

Tonomari K (1988) A rat antibody against a structure functionally related to the mouse T cell receptor/T3 complex Immunogenetics 28 455-458

Welsh AO and Enders AC (1983) Occlusion and reformation of the rat uterine lumen during pregnancy American Journal of Anatomy 167 463-477

Yelavarthi KK, Chen H-L, Yang Y, Cowley BD, Fishback JL and Hunt JS (1991) Tumor necrosis factor-alpha mRNA and protein in rat uterine and placental cells Journal of Immunology 146 3840-3848 